\title{
How to Optimize the Commission Allocation
}

\author{
Lan YI, Wan-Ling LI \\ Economics and Management School of Wuhan University, Wuhan 430072, China \\ China Resources Vanguard. Co., Ltd, Shenzhen 518020, China \\ lanyi66@aliyun.com,liwanling1@crvanguard.com.cn
}

\begin{abstract}
- in this paper, the commission allocation mechanism between the mobile application store and the mobile application developer is studied under the game theory. Firstly, based on the non-cooperative game theory, the paper researches the equilibrium solution of the inter-firm game under the conditions of different sales scale, and then extend the study to the circumstance of infinite game. In addition, the paper analyzes the Pareto improvement achieved by choosing cooperative strategy of strategic alliance from different parts. Finally, problem of the commission allocation problem is resolved.
\end{abstract}

\section{Introduction}

Apple Corporation announced part of its Apple Store sales data in Sept, 2016, it showed that over 0.7 billion iPhone, iPad and iPod's global user had downloaded totally 140 billion applications through the Apple Store. The Apple user paid more than 1.1 billion US\$ in S1 of 2016 and the Apple store had created 1.9 million jobs in USA, 1.2 million jobs in Europe and 1.4 million jobs in China .

The application store not only provided tens of thousands of software to the mobile phone's user, it also created a highly effective marketing channel to application exploiter to reached the end-user directly. Through reviewing various mobile phone's application stores and the application developer's payment allocation model, it is discovered that most application store seek a fix percentage of commission from the developer's application sales. For instance, Apple's App Store, is gaining approximately 20\% to $30 \%$ of its total sales from the application store. Base on the current fix commission basis, is this sufficient to motivate application developer to provide high quality application? Does the commission vary between higher qualities versus normal qualities application developers? How does the total income change if both parties formed strategic alliance cooperation? How does the commission allocated reasonably between both parties? This article will analyze and provide answer to these questions.

\section{Literature Review}

Jeuland and Shugan(1983), Monahan(1984), Moorthy (1987), Cachon and Lariviere(2005) and other scholars suggested various methods to coordinates both parties through the studies of cooperation model between the marketing channel and upstream supplier. One of the methods that they suggested is to allocate a certain percentage of the sales income between upstream and downstream corporation.

The contract among supply chain members that focuses on income mechanism has continuously being studied extensively by scholars. Tsay and Lovejoy (1999), Anupindi and Bassok (1999) and other scholars referenced the cooperation model between the marketing channel and supplier, and the overall supply chain as a foundation for model establishment. Based on the foundation, types of foundation model have been discussed, including the price adjustment, the returns of income, quantity elasticity and other utilization of the rewards and penalty mechanism.

Li, Wang and Zhao (2009) have applied the game theory on departmental store and specialist retailers as a breakthrough point. The studies suggest fluctuation commission cooperation model depending on the sales volume adjustment of the upstream and downstream manufacturer's income distribution. The studies also pointed out the suitable range of sales volume for the model.

Based on the income sharing mechanism, Chen and Gao (2006) suggest the general model for multi-stages supply chain coordinates which analyzes the win-win condition for the members that involves in the supply chain. Lin and Zhu 
(2004) considered introduce the penalty mechanism to improve game theory for income sharing mechanism. Graham (1999), Landeros (1995) and other scholars continued to expand the studies regarding the above literature review that discussed issues on cooperation model between the marketing channel and supplier. They emphasized that the importance of promise and effectiveness in optimizing relations.

Landerous(1995) et al. summarized various factors that restrict win-win outcome of the alliance between the upstream and downstream manufacturer. Furthermore, Coughlan (2001) pointed out that both parties will have great difficulties to perform a full cooperation if upstream supplier and downstream retailer both position themselves in a rational supposition that only pursues own benefit maximization. Under this circumstances, it would be a challenge to optimize the returns of the overall supply chain.

In the recent research, scholars started studying the cooperation organization structure within the channel. The studies tend to focus on "partnership" and "alliance" cooperation, it is believe that this kind of cooperation mechanism will be helpful in enhancing the confidence level as well as reduces the transaction cost. As a whole, presently the academia research outcome provided various valuable theories for the cooperation model between the application store and exploiters. However, the current theory is incapably to explain the choice of cooperate model under some specific market environment (for example, the internet market environment). Moreover, within the academia there is lack of analysis regarding key factors that influences the cooperation model, such as, sales volume.

In addition, most studies focuses on the rational supposition that only pursues own benefit maximization of the upstream and downstream manufacturer, there are lack of studies that concentrate on cooperation game theory perspective based on the collective rationality to analyze bilateral game theory relations. Therefore, this article attempts to have the different view on these two new perspectives.

\section{Non-Cooperate Perspective Game Theory Model}

Firstly in this section, we will established the non-cooperate perspective game theory model, by identifying the basic game theory environment between the application store and the application exploiter under the scope of internet market background.

Secondly, we will discuss the dynamic influence between the bilateral game theory and sales volume balances under the game theory in a static situation.

Finally, we will expand the game theory from single phase to multiple phases, in order to analyze the changes in strategic selection and other condition of the bilateral longterm cooperative game.

\subsection{Basic assumptions and definitions}

We make assumptions for bilateral game conditions based on the characteristics of the internet market, bilateral game and mobile phones application products:

Assumption 1: Market characteristics

Internet is a perfect channel to access complete information and the cost of the information flow is extremely low; assuming that all mobile phone application product is at a very low price and the price maintain at the same level; application store does not have the right and unable to restrict the exploiter to develop application sales channel through internet; internet search engine will be able to provide excellent promotion service for the developer's website.

Assumption 2: bilateral game

Application store and developers are completely rational, both parties receives fully symmetrical information. The application store has two strategic choices to adopt fixed commission or variable commission basis as a source of return; developer has also two strategic choices to create or not create its own sales channel through website.

Assume that the research and development cost for mobile phone application equals to " $D$ ", marginal cost for the production and sales of the application equals to zero. Investment of developer's sales channel in the website equals to "I", developer's website can implement its advertisement promotion through internet search engine or individual website, the advertisement expenses has direct relation with "click quantity", and therefore, it is correlated to sales volume, assume that "r" equals to internet promotion expense per selling unit. Under the circumstances when future sales are unfavorable and the visit quantity of the application store cannot be guaranteed, developers will choose to sell its application in the application store as their first priority.

\subsection{Game model based on fixed commission cooperative basis}

Based on the assumptions above, the profit function of developer's application sales in the application stores equals to:

$$
\pi_{s}=P Q(1-K)-D
$$

If developer create another sales channel and adopted internet as its advertisement promotion then the profit functions equals to:

$$
\pi_{o}=Q(P-r)-I-D
$$

$\pi$ in function (1) and (2) equals to corporate profit, " $P$ " equals to selling price of the application, " $Q$ " equals to selling quantity, " $K$ " equals to sales commission returns of the application store (this section refers to fixed commission, therefore, " $K$ " equals to a constant value), " $r$ " equals to 
coefficient of internet promotion expense, " $P$ " equals to developer's cost of self-developed internet sales channel, " $D$ " equals to application research and development cost.

Sales channel developed by application developers will cause decrease in sales of the relevant applications in the application store. Assume that the total social demand stays constant, dependent variable " $\lambda$ " equals to the proportion of application sales volume of the total sales volume, after the developers created its own internet sales channel.

Therefore, after the developers created another channel, two sources of sales returns will be recognize which includes:

$$
\begin{gathered}
\pi_{s s}=\lambda P Q(1-K)-D(3) \\
\pi_{s o}=(1-\lambda) Q(P-r)-I-D(4)
\end{gathered}
$$

The condition for the developers to create its own internet sales channel is the total sales returns of both channel is larger than the return of application that only distribute in the application store, then, $(1) \leq(3)+(4)$.

As a result, inequality of function (5) is the condition for the developers to create its own internet sales channel:

$$
(P K-r) Q \geq \frac{I}{1-\lambda}(5)
$$

As $\mathrm{P}$ is a constant value, therefore, when $P K \leq r$, it suggests that the promotion expense will be higher if developer creates its own internet sales channel, furthermore, the proportion of the sales return is lower in the application store. As a result, it is not economical for the developers to create its own internet sales channel, therefore, function(5)does not establish.

When $P K \geq r$, it suggests that the advertising expense will be lower if developer creates its own internet sales channel, conversely, the proportion of the sales return is higher in the application store. Developers can choose to create its own internet sales channel, but the condition is that the sales volume does not satisfy function (6):

$$
Q \geq \frac{I}{(1-\lambda)(P K-r)}
$$

If fixed commission is constantly used while the sales volume of the application is in a very high level, then the developers would probably shift their selling distribution to other marketing channel. Although it results in extra cost for developer to create another channel, it reduces developer's commission expense for the application store. In such circumstances, developer's basic trade-off is the cost of the marketing channel and commission, and the main factor that influences trade-off is the sales volume.

Proposition 1: When the developer creates its own internet sales channel advertising expense is lower, application store's proportion of sales return is higher, the relationships satisfy $P K \geq r$, and the sales volume satisfy
$Q \geq \frac{I}{(1-\lambda)(P K-r)}$, then developer will choose to create internet sales channel other than the application store.

\section{Game Model Based on Variable Commission Cooperative Basis}

When application sales volume satisfies function (6), then developer will create extra internet sales channel, this strategy not only increase its return, it also reduce the return of the application store. Under such circumstances, application store will consider adopting variable commission strategy which will decrease commission proportion from the higher sales application developers; ultimately it will reduce the motive of the developers to distribute its application in other internet sales channel.

Variable commission strategy is defined as the proportion return of the application store will vary according to the sales fluctuation of the developers. This economic significance is that the application stores provide rent return to developers as a reward through transferring partial income to developers which will reduce the motive of the developers to distribute in other channel.

Meanwhile, application store faces the basic trade-off, which is to shift the return losses and return brings from developers that not distribute in other channel. The core factor that influences this trade-off is the demand of the application. Therefore, application store should only provide proportion of the variable commission that satisfies the conditions below: (1) from the developer's perspective, the effectiveness is indifferent whether it creates or not creates distribution in other channel; (2) under the condition where return of application store is larger than the proportion of fixed commission, the developer favor the return from the application store rather than the return in internet channel.

When the market demand satisfies function (6) and (1) = (3) + (4), resulting the function of application store's variable commission present as shown below:

$$
K_{m}=\frac{I+(1-\lambda) Q r}{P Q(1-\lambda)}=\frac{I}{P Q(1-\lambda)}+\frac{r}{P}
$$

From function (7) it is found that, when developer's cost of self-developed internet sales channel " $I$ " and internet promotion expense per selling unit " $r$ " is higher, then the proportion of variable commission " $K_{m}$ " can be set in a higher level. Under such circumstances, it is sufficient for the application store to transfer minimal payment to prevent developers to distribute in other channel.

When the sales volume divergence of the application developers influence by the developers distributing in other channel are relatively low and " $\lambda$ "is larger, then proportion of $K_{m}$ will be higher.

It is because, meanwhile consumer are more willing to purchase application in the application store (which makes application store higher selling share). As a result, the 
application store has stronger bargaining power than developers during the game.

Similarly, it is sufficient for the application store to transfer minimal payment to prevent developers to distribute in other channel, which will guaranteed the return of the application stores.

When the market response of the developer product is favorable (when sales volume " $Q$ " is larger), the bargaining power of developers will be stronger, then application store will need to reduce the cost of developer.

Proposition 2: When application store adopt a variable commission basis, then the value can be express as $K_{m}=\frac{I}{P Q(1-\lambda)}+\frac{r}{P}$, the commission proportion will be positively relation to " $I$,, $r$ ", “ $\lambda$ "; and negatively relation to sales volume " $Q$ ", therefore, the developer's return is indifferent regardless it creates or not creates distribution in other channel.

Expression (7) can reference by the application store to design the proportion of variable commission, the better practical value for " $I ", " r$ ", “ $\lambda$ " and " $Q$ " can be obtain through market research.

Thus, the application store fixed commission model may not be the golden rule, an application store should recognize the scope of various cooperative model, should alter the cooperative model that best suits the market and internal characteristics.

\subsection{Game model based on non cooperative perspective}

\section{1) Static game model}

In static game model, application store has two strategies which involves fixed and variable commission basis. Developer has also two strategies which are create or not create its own internet selling channel. These strategies can be express as the diagram below:

TABLE I. TABLE 1 EXPRESSION OF GAME STRATEGIES FOR BOTH PARTIES

\begin{tabular}{|c|c|c|c|}
\hline & \multicolumn{2}{|l|}{ developers } \\
\hline & & $\begin{array}{l}\text { Create internet sales } \\
\text { channel }\end{array}$ & $\begin{array}{c}\text { Not create } \\
\text { internet sales } \\
\text { channel }\end{array}$ \\
\hline 高 & $\begin{array}{c}\text { Fix } \\
\text { commissio } \\
\mathrm{n} \text { basis }\end{array}$ & $\begin{array}{c}P Q(1-\lambda K)-r Q(1-\lambda)-D-I \\
(8) \\
P Q \lambda K-C(9)\end{array}$ & $\begin{array}{c}P Q(1-K)-D \\
P Q K-C(10)\end{array}$ \\
\hline
\end{tabular}

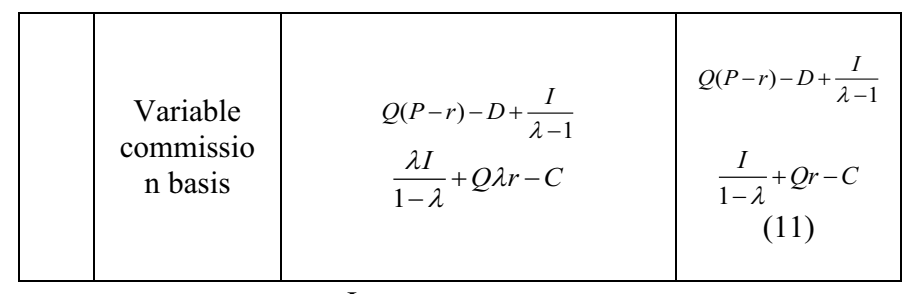

When $Q \geq \frac{I}{(1-\lambda)(P K-r)}$ is within the selling scope, and if, application store choose fixed commission basis, then creating an internet sales channel is a dominant strategy for developer.

If application store choose to adopt variable commission basis, then the developer's return is indifferent whether it creates or not creates distribution in other channel. Therefore, regardless of any strategy that the application store adopts, when the sales volume reaches $Q \geq \frac{I}{(1-\lambda)(P K-r)}$ then creating an internet sales channel is a dominant strategy for developer.

Under such circumstances, application store will adopt fixed commission basis, because developer is unable to alter its internet sales channel strategy under variable commission basis, therefore, combination strategy of fixed commission basis and creating internet sales channel as the Nash equilibrium solution for this game model.

Proposition 3:When sales volume of the application satisfies $Q \geq \frac{I}{(1-\lambda)(P K-r)}$ application store would select a strategy of fixed commission basis and creating internet sales channel as the Nash equilibrium solution for this game model.

When sales volume of the application satisfies $\frac{I}{(1-\lambda)(P K-r)} \leq Q \leq \frac{I}{(1-\lambda)(P \lambda K-r)}$, the return is greater when selecting "variable commission basis and not create its own internet selling channel" strategy in comparison to "fixed commission basis and creating internet sales channel" strategy; which can be express as $\frac{I}{1-\lambda}+Q r-C \geq$ $P Q \lambda K-C$

If application store choose a variable commission basis $K_{m}=\frac{I}{P Q(1-\lambda)}+\frac{r}{P}$ causing the return of the applications developer to be equal, then developers will choose not to create its own internet selling channel.

Proposition 4:When sales volume of the application satisfy:

$$
\frac{I}{(1-\lambda)(P K-r)} \leq Q \leq \frac{I}{(1-\lambda)(P \lambda K-r)} \quad, \text { then the }
$$

choice of the application store can be express $K_{m}=\frac{I}{P Q(1-\lambda)}+\frac{r}{P}$, a variable commission basis. If 
developer choose not to create its own internet selling channel in such condition, then (variable commission, not create internet channel) it will become Pareto Improvement payment combination.

However, Pareto Improvement in proposition 4 cannot be achieving in a sustainable manner when the game is in a static situation. It is because the equilibrium condition does not satisfy the rational supposition under the condition of non-cooperative game theory.

Once rational developer anticipated that the strategy of not to create an internet channel, then developer will choose fix commission strategy under the principle of self-interest maximization which will earn a return from divergence agreement.

It does not make any sense for application store and developer to negotiate in the early stage of the cooperation, simply because, this Pareto Improvement payment combination does not form an equilibrium solution; both parties will not proactively compliance with commitments. In summary, under the condition where sales volume of the application is moderate, then both parties will face a Prisoner's Dilemma, an equilibrium solution will be fixed commission basis and creating internet sales channel strategy.

When the sales volume of the application continues to growth $Q \geq \frac{I}{(1-\lambda)(P \lambda K-r)}$, then the return would be smaller if variable commission has been selected over fixed commission basis, can be express as $\frac{I}{1-\lambda}+Q r-C \leq$ $P Q \lambda K-C$.

Variable commission of the application store can be expressed as $K_{m}=\frac{I}{P Q(1-\lambda)}+\frac{r}{P}$ and $\frac{d K_{m}}{d Q}<0$, when the sales reaches certain extent, the expense of shifting a source of income is greater than the losses in return from the fix commission basis. Therefore, sales volume within certain range, application store will insist a fix commission basis and developer will also create an internet sales channel strategy.

Proposition 5: When sales volume of the application reaches $Q \geq \frac{I}{(1-\lambda)(P \lambda K-r)}$ then equilibrium solution for application store and developer will be: application store select a fixed commission basis and developer create its own internet selling channel.

Based on above proposition, it can be seen that game balance between the application store and developer is determined by the sales changes of the application.

\subsection{Repeated game model}

In this section, we discussed the changes of the long-term cooperation model between the application store and developer. It is also to expand static game model, which has been discussed in last section, into multiple period repeated game model.

\subsubsection{Finitely repeated game}

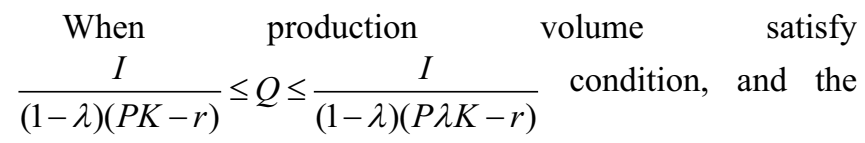
game period between the application store and developer are limited, then the subgame perfect Nash equilibrium can be determine via backward induction which is fixed commission basis and creating internet sales channel strategy. This prisoner dilemma will never ever reaches Pareto Improvement (variable commission basis and developer not to create its own internet selling channel)

\subsubsection{Infinitely repeated game model}

Assume that game has repeated infinitely, we considered that both parties will adopt a trigger strategy as equilibrium game. Application developer's trigger strategy is initially insisted not create its own internet selling channel until a period when application store chosen a fixed commission strategy; developer will continue to create its own internet selling channel as a retaliation.

From the application store's perspective, when it selected variable commission basis, both strategies that the developer selected will make no different. Therefore, it will not be concern if application store's adopt a trigger strategy when developer departure from the contract. Assume that $\delta$ as stochastic discount factor of application store.

If application store departure from the contract and selected a fixed commission basis at any stage of the game, then return of the relevant period will be $P Q K-C$; and the additional return compared to the previous contract can be express as $Q(P K-r)-\frac{I}{1-\lambda}$.

However, opportunistic behavior of the application store will trigger developer to create its own internet selling channel forever as a punishment. At this stage, return of the application store ${ }_{\text {will }}$ reduce $P Q \lambda K-C$ in each period.

Therefore, if conditions below are satisfied, then application store will not departure from the contract to choose a fixed commission strategy in any given period:

$$
\begin{aligned}
& {\left[Q(P K-r)-\frac{I}{1-\lambda}\right]+\delta[P Q \lambda K-C]+\delta^{2}[P Q \lambda K-C]+\cdots \cdots \leq} \\
& \quad\left(\frac{I}{1-\lambda}+Q r-C\right)+\delta\left(\frac{I}{1-\lambda}+Q r-C\right)+\delta^{2}\left(\frac{I}{1-\lambda}+Q r-C\right)+\cdots \\
& \text { Conditions above can be solved as: }
\end{aligned}
$$




$$
\delta^{*} \geq \frac{C+P Q K-2 Q r-\frac{2 I}{1-\lambda}}{C+P K Q-P Q \lambda K-Q r-\frac{I}{1-\lambda}}
$$

$\delta^{*}$ means the level of important of the future return to application store. When present discounted value in the future satisfies condition (12), then application store will never choose to exploit developer at any point of time.

Therefore, both parties trigger strategy is in sub game perfect Nash equilibrium, Pareto improvement (variable commission basis and not to create its own internet selling channel) will be an equilibrium solution in each period. Under such condition, application store and developer resolve the finitely game dilemma.

The reason behind this is, if game repeated infinitely and each participant has enough patience, then the return of any short-term opportunistic behavior is minimal. If the return of application store's present discounted value does not satisfy condition (12), then Pareto improvement (variable commission basis and not to create its own internet selling channel) will not achieve. Proposition 6 has been obtained as a result of above analysis.

Proposition 6:If the game between the application store and developer repeated finitely, (fix commission basis, create internet channel) is the equilibrium solution of each period. Only the game repeat infinitely and the app store's present discounted value ratio satisfy condition (12), the strategy (variable commission basis and not to create its own internet selling channel) will be sub game perfect Nash equilibrium then Pareto improvement achieve.

All in sum, if the partners want to obtain higher return, they should abandon the short-sighted current cooperation idea and develop a long-term and steady cooperation relationship. The longer they cooperate, the higher the return will be.

In the analysis of this section, although the solution to Pareto improvement of two parties came upon, we can get a greater discounted value solely assuming the two parties' long-term gamble and app store. And can the two sides cooperate without the assumptions? If so, how the two parties distribute the cooperating surplus? Next we make a penetrating analysis of the problem based on cooperating game theory.

\section{The Theory Model on Cooperative Game Perspective}

On the basic of the above, a deep issue is the conflict between individual and collective rationality. To more definitely, application store and developer are based on optimal self-utility, only to find losses of the common interests. Supposing that the two sides form the strategic alliance to make more profit rather than trade for the market, we can approach that how the two parties sign the binding cooperative agreement and improve Pareto according to cooperative game theory.
With cooperative game, cooperative parties pay attention to individual rationality instead of collective rationality. In the model, although there is a conflict between individual rationality and collective rationality, the two-party-payingterm raises efficiency and gets the Pareto improvement when cooperating. The core is, the two sides in strategic alliance design a binding mechanism in order to come to equilibrium fairly and effectively. In other words, they get variable commission and do not develop a news channel. What's more, they get surplus by distributing in reason so as to establish a stable cooperative relationship.

For there is no a definite solution to explain 'fair', there is no Nash equilibrium in cooperative game theory in the same way. Even so, with the development of cooperative game theory, a lot of effective solutions have been introduced, in which there is the significant and generally acceptable Shapley Value. With Shapley Value, we elaborate cooperative mechanism between app store and developer.

For app store and develop in strategic alliance, surplus coming from cooperation is

$Q(P-r)-D+\frac{I}{\lambda-1}+\frac{I}{1-\lambda}+Q r-C=P Q-D-C$. If wanting to reach a binding agreement and get the common income, they need to use Shapley Value to calculate how many they should get from the surplus.

Strictly for developer, the Shapley value is

$$
\frac{0 !(1 !)}{2 !}[P Q(1-\lambda K)-r Q(1-\lambda)-D-I-0]+\frac{1 !(0 !)}{2 !}[P Q-D-C-(P Q \lambda K-C)]
$$

$$
=P Q(1-\lambda \mathrm{K})-\mathrm{D}-\frac{1}{2}(\mathrm{Q}-\lambda \mathrm{Q}+\mathrm{I})(13)
$$

Proposition $7: \because$ In the relationship of strategic cooperate game, the software store should share the final benefit from

$$
P Q(1-\lambda \mathrm{K})-\mathrm{D}-\frac{1}{2}(\mathrm{Q}-\lambda \mathrm{Q}+\mathrm{I})
$$

Likewise, for app store, the Shapley Value is

$$
\begin{gathered}
\frac{0 !(1 !)}{2 !}[P Q \lambda K-C-0]+\frac{1 !(0 !)}{2 !}[P Q-D-C-(P Q(1-\lambda K)-r Q(1-\lambda)-D-I)] \\
=P Q \lambda K-C+\frac{1}{2}(Q-\lambda Q+I)
\end{gathered}
$$

Proposition 8:In the relationship of strategic cooperate game, the software store should share the final benefit from

$$
P Q \lambda K-C+\frac{1}{2}(Q-\lambda Q+I)
$$

The difference benefit of developer got from cooperative and non-cooperative is: $(1-\lambda)\left(r+\frac{1}{2}\right) Q+\frac{I}{2}:(13-8)$. The positive value means that cooperative model of developer would get much more than non-cooperative. App store 
would get $\frac{Q}{2}(1-\lambda)+I$ in the same way. Above all, the two equations prove cooperative model is better than noncooperative in this situation. Shapley Value indicates the value of cooperative working. The conclusion has been proved by economy authorities on the fair and effective of this model. Therefore, the model is a powerful evidence of cooperate and distribute the surplus between application store and developer.

\section{Conclusion and Discussion}

Studying the cooperative model between mobile application stores and developers, the paper extends and analyses dynamic and static non-cooperative and cooperative model, based on cooperative and non-cooperative game theory. It tries to analyze the selections and their influential factors of various business competitive and cooperative relative enterprises. Proposition 5 under the dynamic game theory of complete information indicates that sales of products determines competitive pattern. More importantly, we find that the fixed division proportion system prevailing in current market is not the most scientific or effective. So when designing cooperation model of application store, every main operator and phone manufacturer in our country is supposed to create a new cooperative mechanism according to its local conditions instead of entirely aping the business model of the application store. It is proved by proposition 6 of repeated game model that a balanced cooperative model is decided by cooperative agreement in the case of a long-term cooperation between both sides. In other words, the longer the expected mutual cooperation, the bigger possibilities of Pareto improvement. Thus we can draw a conclusion that the following ways determine sharing and personal profit between application stores and developers. Firstly, under the background of Internet sales model, application stores and developers should identify the market demand and product characteristics, having a good understanding on and realistic expectation about them. Secondly, either party has to establish steady and long-term relationship. For instance, they use cooperative ways of strategic alliance, cross shareholding and joint venture especially mergers and acquisitions, which change one-off deal into long-term relationship.

In addition, with the cooperative game theory, the allocation of the sharing benefits on cooperative parties is analyzed. Specifically, the paper, under proposition 7 and 8 of cooperative game theory model, shows how to fairly and effectively distribute the surplus, improved by cooperation and Pareto between both sides, who aim at collective rationality. Therefore, according to the observation, application stores and developers can sign a binding contract so as to guarantee the cooperation and maximum profits between the two parties.

\section{References}

[1] Jeuland,Abel P., Steven M.Shugan. Managing Channel Profits. Marketing Science, 1983, 2(3):239-272.

[2] J.Monahan.A Quantity Discount Pricing Model to Increase Vendor Profits . Management Science , 1984(30):720-726

[3] K.S.Moorthy, Managing channel profits:Comments, Marketing Science 6, 1987:375 379.

[4] Cachon, Gérard P., Martin A. Lariviere.Supply Chain Coordination with Revenue-Sharing Contracts: Strengths and Limitations.Management Science, 2005, 51(1):30-44.

[5] TsayA.,Lovejoy.W. Quantity flexibility contracts and supply chainperformance. Manufacturing and Service Operations Management,1,1999:89 111

[6] AnupindiR.and Bassok .Y. Centralization of stocks: Retailers vs.Manufacturer .Management Science,45,1999:178 191

[7] Coughlan Anne T, Erin Anderson, Louis W. marketing channels. Sixth Edition,Printice Hall, 2001

[8] Graham T S,Daugherty P J,Dudley W N. The Longterm Strategic Impact of Purchasing Partnership. InternationalJournal of Purchasing and Materials Management, 1994,30(4):

[9] 13-18

[10] Landeros R,Reck Ret al. Maintaining Buyer-supplier Partnerships. InternationalJournal of Purchasing and Materials Management,1995,31(3):3-11

[11] Guillermo Owen, Game Theory. Second Edition, Academic Press, 1982

[12] Lin,Xudong,Shunquan Zhu.Study on Game Model of Profit Distribution in Supply Chain Corporation.Value Engineering,2004,23(5): 29-31.

[13] Li,Hao, Gao Wang, Ping Zhao.Employing float commission rate to optimize the revenue-sharing mechanism.Journal of systems engineering, 2011,26(3): 352-359

[14] Chen, Fuhua, ChengxiuGao. Multi-Stage Supply Chain Coordination by Revenue Sharing Contracts. Journal Of Wuhan University(Natural Science Edition), 2006, 52(3): 291-295.

[15] Chen, Yuanzhi, Jianming, xia.Establishment and Operation of the Model of Supply Chain Management Strategy.Journal of Finance and Economics,2004,30(3): 75-84.

[16] Sun, Penggui.Supply Chain Mangement and Enterprises's Relation Strategy[J].Journal of Finance and Economics,2002,28(4):58-63.

[17] Zhang, Weiying, Game Theory and Information Economics,ShangHaiSanlian Press 